\title{
Control of weld composition when welding high strength aluminium alloy using the tandem process
}

\author{
C. G. Pickin*, S. W. Williams, P. B. Prangnell, J. Robson and M. Lunt
}

\begin{abstract}
A new cost effective process for generating different weld element compositions has been examined. Utilising tandem welding technology, different series aluminium filler wires were mixed in a single weld pool with the result that the composition of the principal alloy elements, copper and magnesium were accurately controlled. Thermodynamic modelling was then used to predict an optimum weld bead composition for eliminating solidification cracking when welding Al2024. In order to validate the predicted target composition, the tandem process was used to control the composition of the weld bead. The presented results show that using this system to deposit a controlled ternary composition weld, solidification cracking was eliminated when welding highly constrained test pieces. In contrast, cracking was evident when using commercially available binary filler wires under the same conditions.
\end{abstract}

Keywords: Tandem welding, High strength aluminium alloys, Filler wire development, Thermodynamic modelling

\section{Introduction}

High strength aluminium alloys have been used extensively in the aerospace industry for many years. These are typically of the ternary $\mathrm{Al}-\mathrm{Cu}-\mathrm{Mg}$ and $\mathrm{Al}-\mathrm{Mg}-\mathrm{Zn}$ system of the 2xxx and 7xxx series of alloys respectively. Recent development of these materials has generated interest from the defence industry where their use in armour applications shows promise.

Manufacture of armoured fighting vehicles (AFVs) has traditionally employed arc welding processes (gas tungsten arc and gas metal arc) due mainly to relative ease of use and single sided operation. The emergence of friction stir welding (FSW) technology is now seen as an attractive joining process due to the advantages offered by comparatively lower heat input and metallurgical improvements which result in enhanced mechanical properties. ${ }^{1-4}$ Friction stir welding does, however, have potential limitations when considering volume production and maintenance of AFVs. In particular, joint design is constrained by the process capabilities and the practicalities of employing the process for in-service repair are yet to be addressed. In these respects, it is likely that arc welding processes will still be employed alongside FSW for future production of AFVs.

When considering arc welding of many ternary high strength aluminium alloys, hot cracking is a common defect. $^{5,6}$ A further interrelated problem is the lack of matching commercial weld filler wires; those that are available are of a binary system typically $\mathrm{Al}-\mathrm{Si}, \mathrm{Al}-\mathrm{Mg}$

Welding Engineering Research Centre, Cranfield University, Bedfordshire, UK

*Corresponding author, email c.g.pickin @ cranfield.ac.uk and $\mathrm{Al}-\mathrm{Cu}$. The result is that defects such as cracking cannot be controlled and final post-weld joint strength is often compromised due to undermatched weld composition.

A number of issues are evident in the development of new filler wires:

(i) cost is prohibitive

(ii) one off prototype filler wires have variable quality

(iii) elemental recipe is subjective

(iv) potentially, a large range of fillers must be developed for the range of alloys.

A number of different approaches have been employed to determine optimum filler wire compositions. Much of this work has focused upon the rare earth element scandium. When this is added to the weld in precise quantities, it has been shown to act as a dispersoid former during solidification. ${ }^{7-9}$ This has the result that grain growth is refined, hot cracking is reduced and post-weld joint strength is enhanced. However, these studies have either employed the use of casting to mimic the composition and properties of the weld or the production of expensive one-off prototype filler wires. ${ }^{10-12}$ While each of these methods has shown benefits, to date no scandium alloyed filler wire is commercially available.

A further approach has been to model the solidification pathways of highly alloyed weld. A notable study examined the addition of copper to control the freezing range of the weld poo ${ }^{13}$ with validation of this approach conducted by simply inserting copper wire into a weld preparation before welding. This method has clear issues notably, mixing cannot be guaranteed nor can the mixing ratio be easily controlled. As a result, the study 
did not conclusively define the optimum copper content of the weld with respect to crack eradication and mechanical strength enhancement.

An additional method has been to twist different series and different diameter gas tungsten arc welding filler wires together to vary weld bead composition. ${ }^{14}$ Although this approach shows promise as a simple, quick and cost effective method of varying composition, it still has the limitation in that inadequate mixing may result. In addition, the twisted wires must be fed manually which introduces further variables.

The objective of this research is to show how by mixing commercially available filler wires using an automated tandem process, the composition of the weld bead can be varied to produce crack free welds based upon a predictive solidification model.

\section{Experimental}

Aluminium alloy $2024 \mathrm{~T} 351(12.7 \mathrm{~mm})$ was used as the base material for this study. For mixing experiments, the investigated elements were copper $(\mathrm{Cu})$ and magnesium $(\mathrm{Mg})$. Trials were conducted using $2319(6 \mathrm{wt}-\% \mathrm{Cu})$ and $5556(5 \mathrm{wt}-\% \mathrm{Mg})$ filler wires of varying diameter. Elemental compositions are detailed in Table 1. Bead on plate welds were performed for these trials.

Bead shape geometry was defined using standard metallographic techniques. The predictive elemental composition of the weld $(E \%)$ at a given dilution ratio was determined using equation (1) where $A b$ is the area of weld penetration and $A f$ is the area of weld reinforcement.

$$
\begin{aligned}
E \% \text { weld }= & (E \% \text { in base metal })[A b /(A b+A f)] \\
& +(E \% \text { in filler })[A f /(A b+A f)]
\end{aligned}
$$

Element composition was measured using energy dispersive X-ray (EDX) analysis on cross-sections taken from the weld.

For assessing crack susceptibility, multirun fillet welds were performed on constrained test pieces. Test pieces of $250 \times 100 \mathrm{~mm}$ were bolted into a steel fixture utilising three M10 bolts per side, tightened to a torque setting of $56 \mathrm{~N}$ m to ensure consistency. Weld sequence is detailed in Fig. 1 with direction and area of element composition measurement arrowed. The sample was allowed to cool to ambient temperature between welds when a visual crack inspection was performed. Each trial was conducted a total of three times to ensure repeatability.

Tandem welding equipment consisted of two Fronius TPS 5000 power sources and a single push-pull torch unit suitable for welding aluminium. The system had the facility to feed filler wires of $1,1.2$ and $1.6 \mathrm{~mm}$ diameters. Operation mode was a combination of spray and pulsed transfer. In particular, the $\mathrm{Cu}$ alloyed filler was employed as the lead filler wire welding in spray transfer with the $\mathrm{Mg}$ alloyed trail wire operating in

Table 1 Compositions of different materials, wt-\%

\begin{tabular}{lllllllll}
\hline Material & Mn & Si & Ti & Mg & Zn & Cr & Fe & Cu \\
\hline Alloy 2024 & $\ldots$ & 0.5 & 0.20 & $1.2-1.8$ & 0.2 & 0.1 & 0.5 & $3 \cdot 8-4.9$ \\
Filler 2319 & 0.3 & 0.2 & 0.15 & 0.02 & 0.1 & $\ldots$ & 0.3 & $5 \cdot 8-6 \cdot 3$ \\
Filler 5556 & 0.1 & 0.2 & 0.20 & $4.7-5.5$ & 0.25 & 0.2 & 0.4 & 0.10 \\
\hline
\end{tabular}

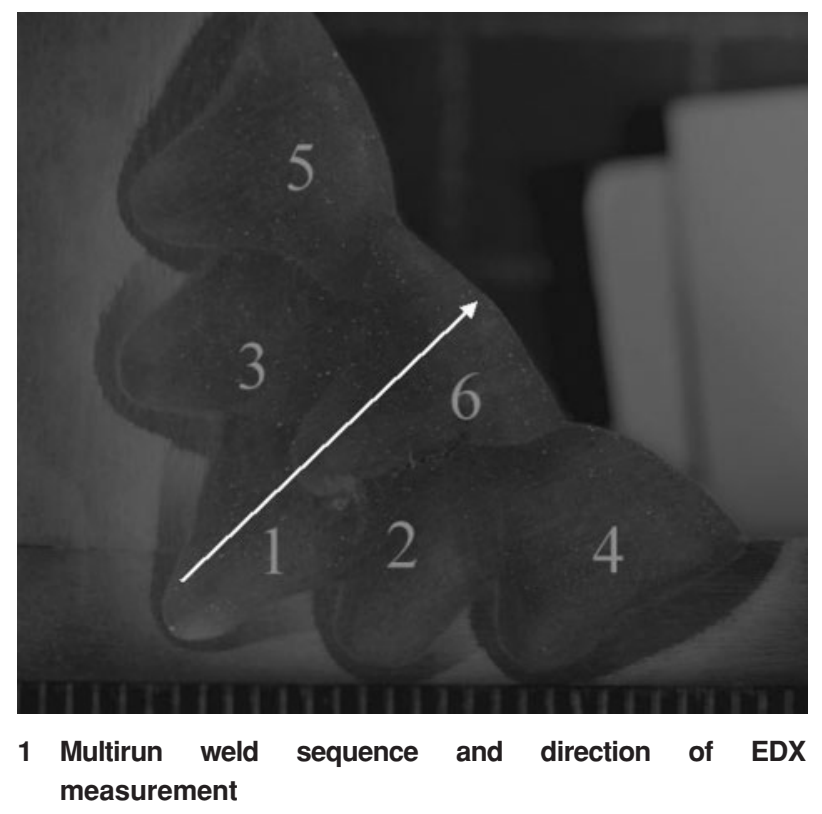

pulsed mode. By mixing two transfer modes, the process was simplified in so far as pulse synchronisation was avoided, i.e. the complexity of synchronising different series filler wires which have different melting coefficients and hence different pulse welding criteria was avoided. In addition, by operating in pulse mode, low wire feedrates could be employed which further increased the mixing range.

\section{Methodology \\ Modelling approach}

Thermodynamic modelling was used to identify the phase relationships of a multicomponent $\mathrm{Al}-\mathrm{Cu}-\mathrm{Mg}$ alloy utilising the CALPHAD method (calculation of phase diagrams). The dataset for this alloy system was MTDATA produced by National Physical Laboratory and has previously been validated to predict the solidification behaviour of 2024 type alloy systems. ${ }^{12}$ However, when fusion welding, solidification occurs under non-equilibrium conditions. In particular, restricted diffusion in the solid phases occurs with the result that equilibrium solidification calculations do not take into account the build-up of solute in the liquid ahead of the solid/liquid interface. In order that fusion zone solidification could be modelled, the equilibrium thermodynamic model was combined with multicomponent Scheil analysis.

Solidification pathways generated by MTDATA depend on the alloy starting composition. By varying this composition, it is possible to map different pathways and determine compositions that solidify with the minimum freezing range. The $\mathrm{Cu}$ content was first fixed for target compositions from 1 to $6 \mathrm{wt}-\%$ and the $\mathrm{Mg}$ content then varied for each $\mathrm{Cu}$ setting. Adopting this approach compositions were modelled whereby the final ternary eutectic freezing range could be minimised. In particular, both the reaction temperatures and the final liquid freezing behaviour could be modelled. An example of this approach is summarised with a fixed $\mathrm{Cu}$ content of $4 \cdot 3 \mathrm{wt}-\%$. 


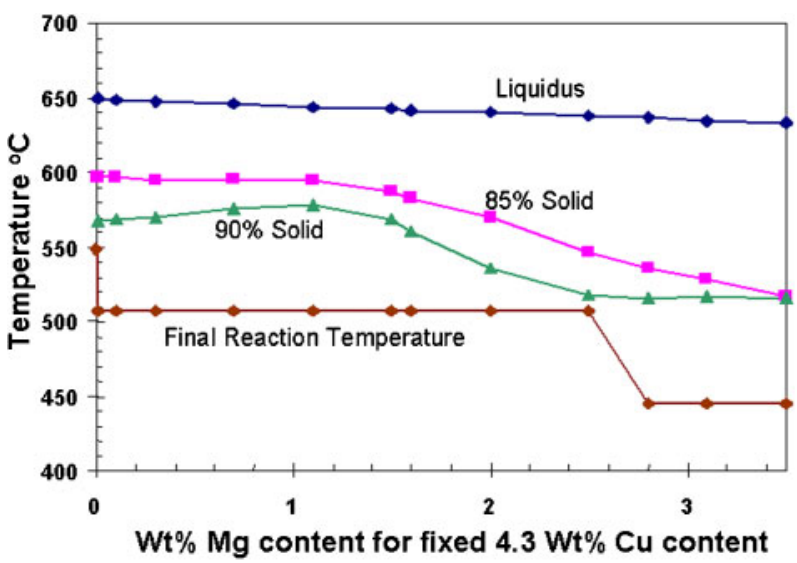

2 Final reaction temperatures for addition of $\mathrm{Mg}(\mathrm{wt}-\%)$ to $4 \cdot 3 \mathrm{wt}-\% \mathrm{Cu}$

\section{Reaction temperatures}

Reaction temperatures for a corresponding increase in $\mathrm{Mg}$ content are shown in Fig. 2. This work identified that only a small change in the liquidus temperature was evident between binary $\mathrm{Al}-4 \cdot 3 \mathrm{Cu}\left(\sim 660^{\circ} \mathrm{C}\right)$ and a ternary composition of $\mathrm{Al}-4 \cdot 3 \mathrm{Cu}-3 \cdot 5 \mathrm{Mg} \quad\left(\sim 630^{\circ} \mathrm{C}\right)$. The final reaction temperature (solidus temperature), dependent on the final isothermal reaction, was calculated as $550^{\circ} \mathrm{C}$ for binary $\mathrm{Al}-4 \cdot 3 \mathrm{Cu}$ and $\sim 505$ or $\sim 450^{\circ} \mathrm{C}$ for the $\mathrm{Al}-\mathrm{Cu}-\mathrm{Mg}$ system. This is, however, dependent on the solidification pathway. For example, formation of the transitional peritectic occurs at $470^{\circ} \mathrm{C}$, this being undesirable as a wide freezing range results. When considering the final reaction temperature in relation to the plot of $90 \%$ solid, the amount of $\mathrm{Mg}$ that can be added to the weld fusion zone is limited when minimising final freezing range.

\section{Final liquid freezing range}

The final liquid freezing range of the eutectic phases was plotted for the same compositions. Reference to Fig. 3 shows that three minima are present. At $0 \mathrm{wt}-\% \mathrm{Mg}$, the binary eutectic $\alpha+\theta\left(\theta-\mathrm{Al}_{2} \mathrm{Cu}\right)$ is formed. Addition of $\mathrm{Mg}$ results in ejection of $\mathrm{Mg}$ into the remaining liquid as the binary eutectic grows. At $\sim 1.6 \mathrm{wt}-\% \mathrm{Mg}$, the $\mathrm{Mg}$ content is high enough for solidification to occur terminating in a ternary eutectic reaction $\alpha+\theta+\mathrm{S}$ $\left(\mathrm{S}-\mathrm{Al}_{2} \mathrm{CuMg}\right)$. Increasing the composition to $\sim 2 \cdot 6$ $\mathrm{wt}-\% \mathrm{Mg}$, the saddle point is reached where a new pseudobinary eutectic reaction, $\alpha+\mathrm{S}$, occurs in the

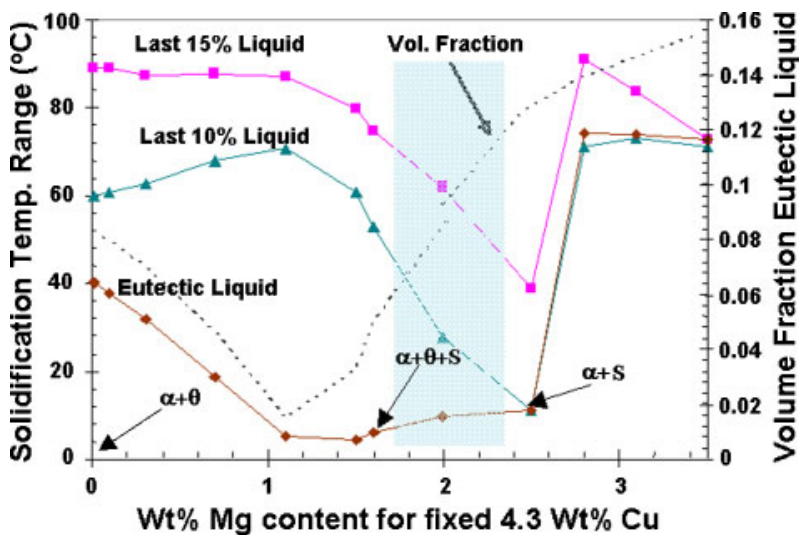

3 Freezing ranges of final liquid and volume fractions of eutectic liquid

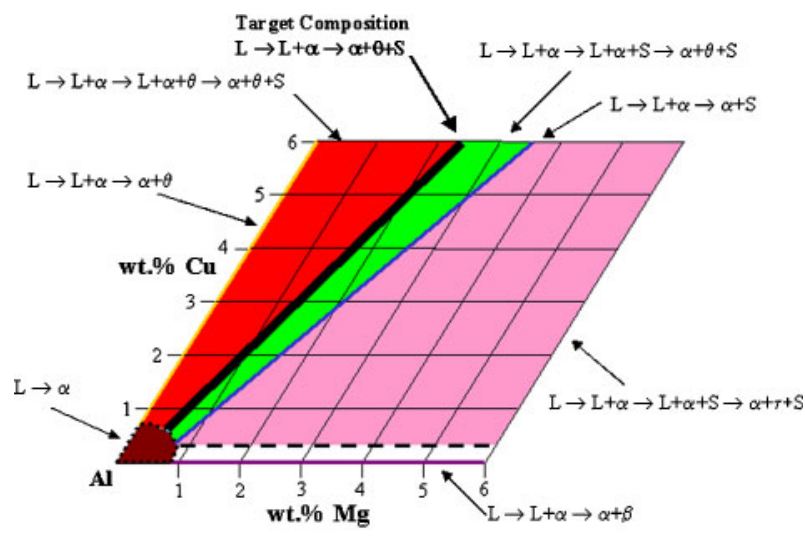

4 Solidification pathways for Al-Cu-Mg alloys using Scheil analysis

remaining $10 \%$ liquid. For $\mathrm{Mg}$ content levels between $\sim 0.2$ and $1.6 \mathrm{wt}-\%$, a comparatively large freezing range is evident over which the eutectic reaction occurs, this varying from 42 to $4^{\circ} \mathrm{C}$. For compositions between the ternary eutectic $(\sim 1.6 \mathrm{wt}-\% \mathrm{Mg})$ and the saddle point $(\sim 2.6 \mathrm{wt}-\% \mathrm{Mg})$, the freezing range for the formation of the non-isothermal eutectic is $4^{\circ} \mathrm{C}$. Within this composition, the last $10 \%$ liquid temperature is low with a large volume fraction, suggesting a target composition range for minimising cracking. Incrementally, increasing the $\mathrm{Mg}$ content beyond the saddle point results in a sharp increase in the eutectic freezing range. As the $\alpha+\mathrm{S}$ eutectic grows, both $\mathrm{Cu}$ and $\mathrm{Mg}$ are ejected into the remaining liquid with complete freezing ultimately terminating in the formation of $\mathrm{T}$ phase, $\mathrm{Mg}_{32}(\mathrm{Al}, \mathrm{Cu})_{49}$.

The solidification pathways for differing $\mathrm{Cu}$ contents are summarised in Fig. 4. Compositions which start as $\alpha-\mathrm{Al}$ and terminate in an isothermal eutectic reaction with minimum freezing range are represented by a solid line indicating a potential target composition. Either side of this line, the red green and pink regions are compositions which start as $\alpha$-Al but terminate in nonisothermal eutectic reactions. Based upon this approach, when considering a target weld composition for alloy 2024 , a composition of $\mathrm{Al}-4 \cdot 5 \mathrm{Cu}-1 \cdot 5 \mathrm{Mg}$ is an obvious choice as this will not only minimise the freezing range, but is similar in composition to the base material.

\section{Mixed alloy tandem welding}

The tandem process was examined for mixing different series of binary filler wires to produce a ternary element weld bead. Predictive compositions regarding filler wire input were determined using mass balance calculations. These were based upon the contents of the principal elements in the filler wire and the total volume determined from the wire feedrate and the diameter of the wire. This assumes that the Lorentz forces in the arc plasma column and Marongoni forces in the weld pool will be sufficient to ensure that adequate mixing occurs. Calculations examining the predicted composition based upon mixing a $2319(6 \mathrm{wt}-\% \mathrm{Cu})$ filler of $1.6 \mathrm{~mm}$ diameter with a $5556(5 \mathrm{wt}-\% \mathrm{Mg})$ filler of $1.2 \mathrm{~mm}$ diameter are shown in Fig. 5. A process window is established for the two elements with the upper limits being defined by the original content of the filler wires. By varying the wire feedrates, i.e. the input parameters, a controlled mixing ratio of these elements can be 

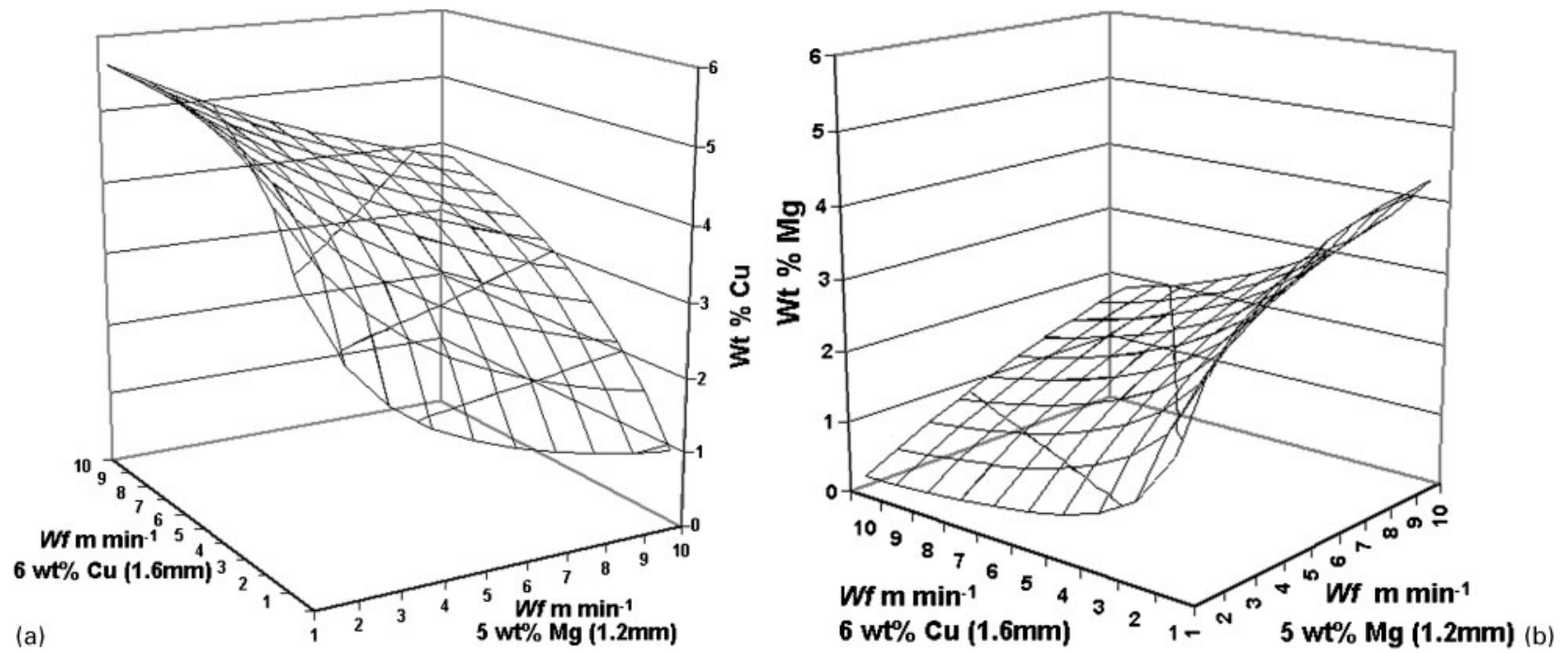

5 a element mixing range of $\mathrm{Cu}$ and $\mathrm{b}$ element mixing range of $\mathrm{Mg}(\mathrm{wt}-\%)$

achieved. By maintaining a constant feedrate for the lead $\mathrm{Cu}$ alloyed filler, the $\mathrm{Mg}$ content can be controlled by varying the feedrate of the trail $\mathrm{Mg}$ alloyed filler wire. However, in increasing the weld $\mathrm{Mg}$ content, a corresponding decrease in $\mathrm{Cu}$ content will result due to volumetric dilution in the deposited weld material. Based upon this approach, the mixing ratio can be controlled to match the model target of $\mathrm{Al}-4 \cdot 5 \mathrm{Cu}-$ $1 \cdot 5 \mathrm{Mg}$. Although the approach determines the input parameters, the effect of weld dilution with the base material must be considered when determining the weld composition. Additionally, input calculations assume a closed system and do not compensate for elemental losses from the filler wire during welding.

\section{Results and discussion}

\section{Mixing of principal elements}

Using the results presented in Fig. 5, bead on plate trials were conducted on the base material. By maintaining a constant wire feedrate of $5 \mathrm{~m} \mathrm{~min}^{-1}$ for the $1.6 \mathrm{~mm}$ $2319 \mathrm{Cu}$ alloyed filler wire, the feedrate for the $1.2 \mathrm{~mm}$ $5556 \mathrm{Mg}$ alloyed wire was varied to control the mixing ratio using wire feedrates of 4,7 and $10 \mathrm{~m} \mathrm{~min}^{-1}$. Crosssections were taken from the weld for determination of the dilution ratio and equation (1) used to predict composition. For greater accuracy, the average EDX

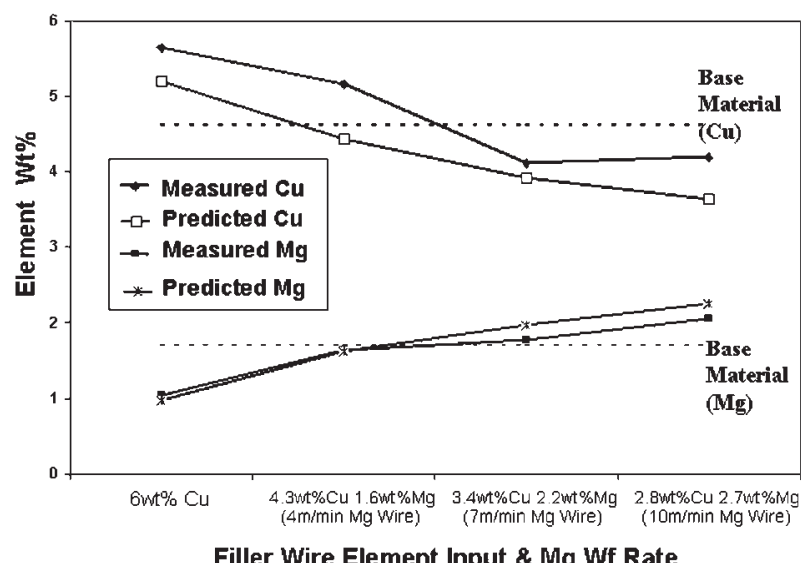

6 Element mixing: measured and predicted values measured composition of the base material was used in the calculations, this being $4 \cdot 6 \mathrm{Cu}-1 \cdot 6 \mathrm{Mg}$. Single wire welds utilising 2319 filler were conducted for comparative purposes. Average measured and predicted values are shown in Fig. 6. A mixing trend is evident for the input values for both $\mathrm{Cu}$ and $\mathrm{Mg}$. While the $\mathrm{Mg}$ composition shows a close match to the predicted values, variation is evident in the $\mathrm{Cu}$ values. Likely causes for this lie in instability due to addition of the trail wire deposition which causes volume changes in the weld pool resulting in arc length fluctuations in the lead wire. The corresponding variation in welding current and hence wire feedrate results in changes to the original input value. Additionally, any element loss to atmosphere appears negligible and is not considered a factor when calculating input values.

\section{Crack assessment}

Comparative trials were conducted depositing single wire welds using binary filler 2319 and the target mixed alloy composition of $\mathrm{Al}-4 \cdot 5 \mathrm{Cu}-1 \cdot 5 \mathrm{Mg}$ deposited using the tandem process. Further trials were conducted using single wire welds using binary filler 5556 .

A test piece was first constructed using 2319 filler where the weld sequence was performed to completion. Reference to Fig. $7 A$ shows solidification cracking through weld 6 that propagates along the length of the weld. On repeating the trial with greater visual inspection, localised cracking was evident in both welds 2 and 3 , although this did not appear visually to propagate along the length of the weld. Reference to Fig. $7 B$ shows that cracking initiates in weld 1 ; however, this only occurs after welds 2 and 3 have been deposited, i.e. cracking is not visually evident in weld 1 when examined in isolation. This indicates that the cracking mechanism is partly due to thermomechanical conditions in addition to composition changes. In particular, remelting of the eutectic phases of weld 1 occurs in addition to further mixing with the composition of welds 2 and 3 . In contrast, the mixed alloy ternary welds did not exhibit any cracking for any of the weld sequences with the result that the test pieces were repeatably welded to completion. A cross-section of these welds is shown in Fig. $7 D$. In comparison to the binary welds, differences are evident in weld bead shape, in particular different 

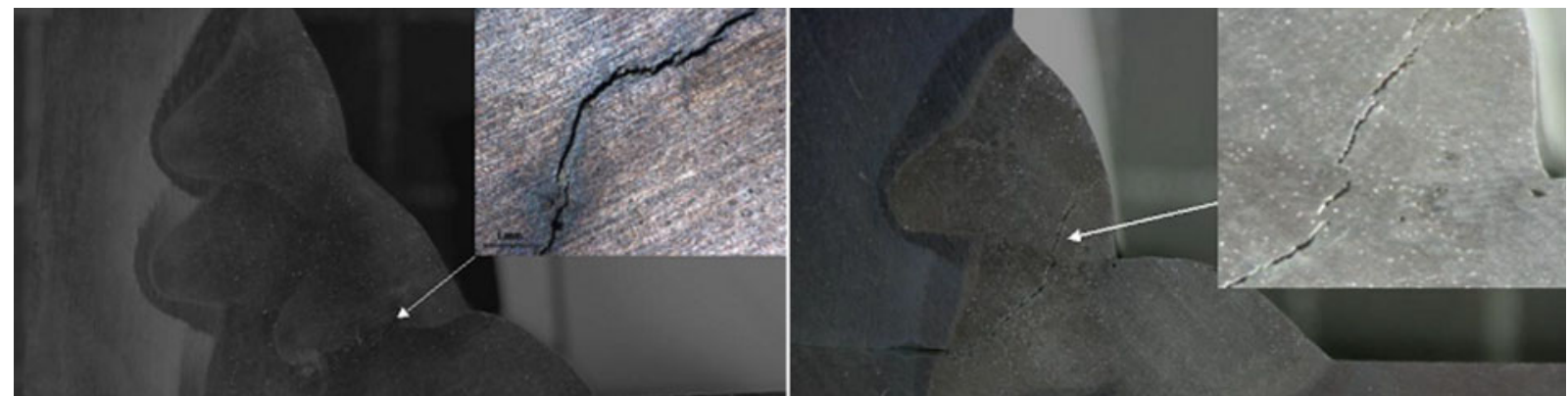

A
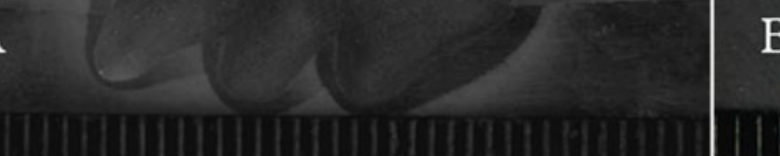

B
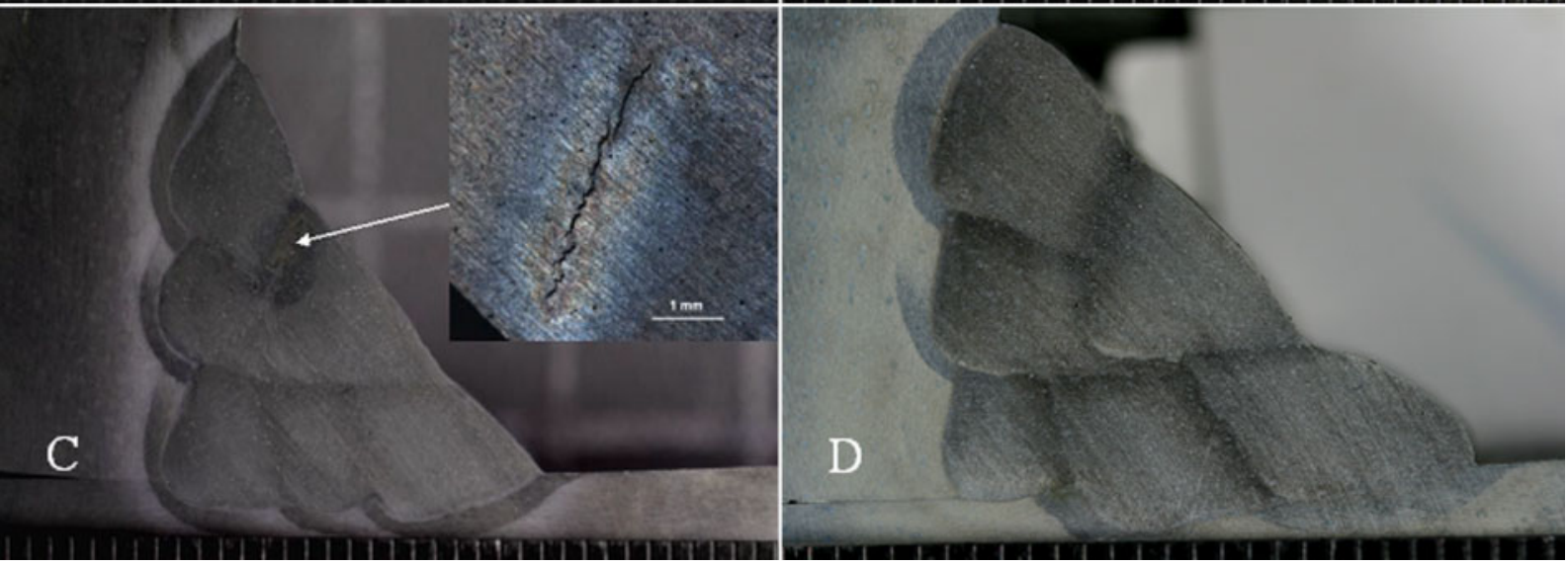

7 A binary 2319 welds showing cracking, B binary 2319 welds sequence 1-3 showing cracking, $C$ reduced deposition binary 2319 welds showing cracking and $D$ ternary $\mathrm{Al}-\mathrm{Cu}-\mathrm{Mg}$ welds no cracking

penetration profiles. Although similar deposition volumes were employed for both trials with similar heat inputs, differences are attributed to the higher welding current (wire feedrate) employed for the single wire weld and the differences in melting coefficients of the two different series wires when employing the tandem system. In order to discount bead geometry as a factor in the cracking of the binary welds, a further test piece was constructed where the weld deposition volume was reduced by $\sim 20 \%$, which also resulted in a reduction in heat input. A similar result was evident with cracking

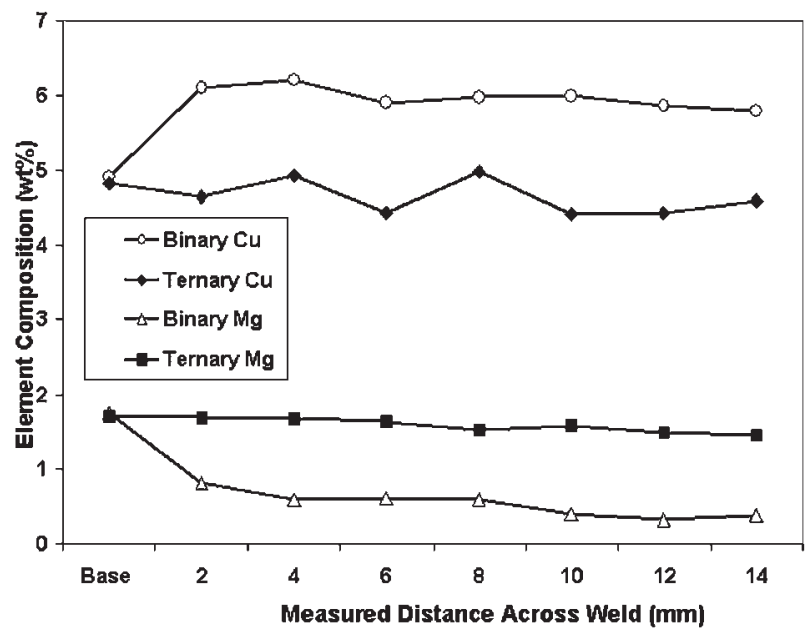

8 Average compositions of multirun fillet welds: binary single wire and tandem ternary alloy welds occurring within the sequence shown in Fig. $7 C$. Although the method of restraint ensured repeatability of the trials, in order to discount this as influencing crack propagation, comparative unconstrained test pieces were produced with the same result.

Comparative compositional analysis is shown in Fig. 8. For binary filler welds, the $\mathrm{Cu}$ content increases and the $\mathrm{Mg}$ content reduces for each successive weld due to the diminishing effect of weld dilution with the base material. This is in the range of $5 \cdot 3 \mathrm{Cu}-0 \cdot 8 \mathrm{Mg}$ at weld 1 to $6 \mathrm{Cu}-0 \cdot 2 \mathrm{Mg}$ at weld 6 . Although weld 6 is close to a binary composition, previous welds in the sequence are in a crack susceptible region of composition. Cracks initiated earlier in the sequence then propagate through weld 6. In contrast, employing the tandem system to deposit a composition matching the modelled target, cracking is eradicated due to the freezing range of the composition being minimised. Additionally, depositing a composition that is approximately the same as the base material with respect to the primary elements, the effect of weld dilution is practically eliminated. Further trials employing 5556 ( $5 \mathrm{wt}-\% \mathrm{Mg}$ ) binary filler wire resulted in severe solidification cracking at weld 1 with the result that further welding as part of the defined sequence was not possible. Elemental composition of these welds was found to be in the region of $1.8 \mathrm{Cu}-3.6 \mathrm{Mg}$. This is in a highly crack susceptible region due to formation of $\mathrm{T}$ phase due to a transitional peritectic reaction resulting in a wide absolute freezing range. Clearly, filler wires rich in $\mathrm{Mg}$ content should never be considered for welding 2024 type ternary alloy systems. 


\section{Further discussion on cracking}

In the current example, the target composition for eliminating solidification cracking is based upon a composition similar to that of the base material. With validation of compositions that differ from the base material, the follow points must be considered. The compositions of both the filler wires and the base material are required. Compositions can, however, vary within specification ranges as detailed in Table 1. Furthermore, the exact dilution ratio is required as this will influence the final composition of the weld bead and will vary depending on material thickness and the filler wires employed due to differences in melting coefficients.

Although not addressed, the effects of varying the compositions of the elements of $\mathrm{Fe}, \mathrm{Si}$ and $\mathrm{Ti}$ present in the base and the filler wires may influence weld solidification and grain refinement. However, when considering the grain refining advantages of particularly $\mathrm{Ti}$ additions, sufficient quantities are present in both filler wires and the base alloy for this to be discounted as influencing the comparative crack results.

\section{Conclusions}

Utilising the tandem welding process to mix different series of filler wires has enabled validation of the model target composition without the requirement to produce a prototype filler wire. The following points are notable:

1. Commercial binary filler wires are incompatible with the ternary structured base alloy when employing multirun welds. The result is that weld solidification cracking occurs.

2. Employing binary $6 \mathrm{wt}-\% \mathrm{Cu}$ filler for multirun welds, wide eutectic freezing ranges occur with each successive weld run due to compositional changes resulting from dilution and mixing with each additional weld run.

3. Mixing filler wires in the tandem system, a ternary $\mathrm{Al}-\mathrm{Cu}-\mathrm{Mg}$ weld bead was produced which matched the predicted value generated from thermodynamic modelling. Repeatable crack free welds were produced.

4. Depositing a weld composition similar to the base material minimises the effect on final composition of weld dilution with the base material.

5. Tandem mixing range when using commercially available filler wires is dependent upon the composition of the fillers.
6. Addition of a third filler wire would greatly increase the range of mixing ratios than is currently realised with a two-wire system.

\section{Acknowledgement}

This work has been conducted as part of the EPSRC/ IMRC sponsored project, Future of Advanced Aluminium Armour (Fuse $-\mathrm{A}^{3}$ ) with funding from the DSTL Joint Academic Research Programme for Defence.

\section{References}

1. V. Dexit, R. Mishra, R. Lederich and R. Talwar: 'Effect of initial temper on mechanical properties of friction stir welded Al-2024 alloy', Sci. Technol. Weld. Join., 2007, 12, (4), 334-340.

2. C. Hamilton, S. Dymek, I. Kalemba and M. Blicharski: 'Friction stir welding of aluminium 7136-T76511 extrusions', Sci. Technol. Weld. Join., 2008, 13, (8), 714-720

3. R. Mishra and Z. Ma: 'Friction stir welding and processing', Mater. Sci. Eng. R, 2005, R50, 1-78.

4. C. Zhou, X. Yang and G. Luang: 'Fatigue properties of friction stir welds in Al 5083 alloy', Scr. Mater., 2005, 53, (10), 1187-1191.

5. C. Huang and S. Kou: 'Liquation mechanisms in multicomponent aluminium alloys during welding', Weld. J., 2002, 81, (10), 211s222s.

6. C. Huang and S. Kou: 'Partially melted zone aluminium welds: liquation mechanisms and directional solidification', Weld. J., 2000, 79, (5), 113s-120s.

7. G. Reddy and A. Mukhopadhyay: 'Influence of scandium on weldability of 7010 aluminium alloy', Sci. Technol. Weld. Join. 2005, 10, (4), 432-441.

8. M. Mousavi and C. Cross: 'Effect of scandium and titanium-boron on grain refinement and hot cracking of aluminium 7108', Sci. Technol. Weld. Join., 1999, 4, (6), 381-388.

9. V. Ryazantsev, A. Filatov and E. Ignatev: 'Selection of filler wire for arc welding aluminium alloys of the $\mathrm{Al}-\mathrm{Mg}$ and $\mathrm{Al}-\mathrm{Cu}$ systems', Weld. Int., 2003, 17, (10), 821-824.

10. S. Rao and G. Reddy: 'Improving mechanical properties of 2219 aluminium alloy GTA welds by scandium addition', Sci. Technol. Weld. Join., 2005, 10, (4), 418-426.

11. A. Norman, S. Birley and P. Pragnell: 'Development of new high strength Al-Sc filler wires for fusion welding 7000 series aluminium aerospace alloys', Sci. Technol. Weld. Join., 2003, 8, (4), 235-345.

12. A. Norman, K. Hyde, S. Birley and P. Pragnell: 'Examination of the effect of scandium on 2000 and 7000 series aluminium alloy castings for improvements in fusion welding', Mater. Sci. Eng. A 2003, A354, 235-245.

13. G. Cao and S. Kou: 'Predicting and reducing liquation cracking susceptibility based up temperature vs. fraction solid', Weld. J., 2006, 85, (1), 9s-18s.

14. K. Sampath: 'Transverse weld tensile properties of a new $\mathrm{Al}-4 \mathrm{Cu}-2 \mathrm{Si}$ alloy as filler metal', Adv. Mater. Processes, 2005, 163, (10), 27-29. 